\title{
Design and Implementation of Mobile Learning Tools and Resources in the Modern Educational Environment of University
}

\author{
Vera I. Toktarova ${ }^{1}$, Anastasiia D. Blagova ${ }^{1}$, Anna V. Filatova ${ }^{1} \&$ Nikolai V. Kuzmin ${ }^{1}$ \\ ${ }^{1}$ Mari State University, Yoshkar-Ola, Russia \\ Correspondence: Vera I. Toktarova, Mari State University, Lenina Sq., 1, Yoshkar-Ola, Republic of Mari El, \\ 424000, Russia.
}

Received: February 21, 2015

Accepted: March 15, 2015

Online Published: April 29, 2015

doi:10.5539/res.v7n8p318

URL: http://dx.doi.org/10.5539/res.v7n8p318

\begin{abstract}
The article introduces the issue of mobile learning in higher education. It examines designing and implementation of mobile learning system in university education process through the use of mobile devices. It explores benefits of m-learning, the basic requirements for mobile learning tools and resources. The article represents the author's m-learning system of programming mobile applications for Android. The results of the study which was carried out with the students of the Applied Mathematics and Informatics Department show high impact mobile learning has on teaching and learning process in higher education.
\end{abstract}

Keywords: mobile learning, informatization of education, programming, m-learning systems, education process, higher education

\section{Introduction}

Active implementation and use of new mobile devices and learning technologies, design of electronic educational resources of the new generation are defined as strategic objectives of the transition to e-learning and indicators of socio-economic efficiency of the implementation of the current Federal Program for the Development of Education. According to the Federal Law "On Education in the Russian Federation", organizations engaged in educational activities, can also use e-learning, distance technologies in the delivery of educational courses (The Federal Law, 2012). Moreover, all necessary conditions should be created for the functioning of informational and educational environment, which is supported by electronic educational resources, information and telecommunication technologies, appropriate technological devices. Rapid development of web technologies and compact mobile devices provide conditions for e-learning, which is, according to the study (Polat et al., 2006; Bondarouk \& Ruël, 2011), a distant interaction between the teacher and students, which reflects all the components of teaching and learning process and is provided through interactive devices.

Nowadays, one of the most effective types of distance and e-learning technologies is mobile learning (mLearning, m-learning). The analysis of global trends in the use of mobile technologies proves the need for the application of mobile devices in the educational activities for achieving a variety of pedagogical aims and providing remote access to learning resources in higher education process. Mobile learning adds new value to the education process, reflects the trends in modern education by providing instant access to information; it is a new tool in the information society, where a new learning environment is created, regardless time and place.

\section{Methods}

The study is based on the results of the following scientific methods:

- Theoretical methods: the study and generalization of domestic and international experience in the designing and implementation of mobile learning in higher education system, analysis of the pedagogical, psychological and technical literature on the informatization of education; inference methods; analysis of regulatory documents, federal state educational standards, curricula, programs, etc.;

- Empirical methods: survey, comparative benchmarking, statistical analysis of the research results, experimental teaching and learning. 


\section{Results}

The use of m-learning is becoming common due to many factors: new social needs in modern educational technologies, the development of market economy, improvement of the learning forms and methods (Al-Qahtani, \& Higgins, 2013).

Various sources define mobile learning as:

- The use of wireless and mobile networks to facilitate, support, enrich learning and provide greater educational coverage (MoLeNET, 2015);

- E-learning through the use of mobile devices (smart-phones, tablets, net-books, handhelds, etc.), that provides mobility to students (GOST, 2011);

- Educational process in which learners gain educational information being away from the traditional learning environment, or such learning which is based on the use of educational opportunities and benefits of mobile technologies (Toktarova, 2013);

- Educational activities through the use of compact and portable devices that allow students to master learning materials more effectively consume and create information (Wexler et al., 2008).

The UNESCO defines mobile learning as the modern ways of supporting the teaching and learning process through the use of mobile technologies, such as handheld computers, MP3 players, smartphones and mobile phones. In this definition, there are references only to technology devices without naming the pedagogical conditions for the implementation of mobile learning.

Analysis of the definitions proves the fact that mobile learning is a many-sided concept. Depending on the goals of the research, scientists study different aspects of mobile learning: theoretical, historical and methodological foundations of mobile learning (Anderson T., Soldatkina V., Tikhomirova E., Lobachyova S., Isaeva Y. et al.); opportunities and principles of the use of handheld computers in education process (Andreev A., Zhukov V., Patarakin E. et al.); experience in designing and application of mobile learning resources (Attevel D., Kuvshinov S., Traxler D., Fedoseyev A. et al.); prospects and opportunities for mobile learning (Kay Alan, Sharples M., Attevel D., Traxler D. et al.).

In order to identify trends in the use of mobile devices and platforms in the higher education environment in Russia, IBS company together with the Russian Public Opinion Research Center have designed and conducted the study in nine federal universities, the aim of which was to estimate penetration rate of mobile devices in the university environment (Ivanchenko, 2013). The target group was students and graduate students, teachers of different disciplines and directions of training and administration officials who are responsible for the implementation of information technologies in the education process. On the whole, the penetration rate of mobile devices in the higher education environment can be defined as very high: $99 \%$ of the students and $95 \%$ of the surveyed teachers have mobile devices. The most common mobile devices among both students and teachers are laptops (83\% and $76 \%$, respectively) and mobile phones with the Internet access $(70 \%$ and $67 \%$, respectively). Moreover, many users often have two or more devices. However, it should be noted that the use of mobile technologies in teaching and learning process in higher education is not widespread and currently there are no accepted standards and specifications on the implementation of e-learning.

In accordance with the results of the study OELPC (2009), we can point out the main requirements for the organization of mobile learning in education system (4C):

- Communication: possibility to communicate through a variety of software tools: e-mail, forums, video-conferencing;

- Collaboration: mobile learning tools and software must be ergonomic and easy to use;

- Creation: e-learning tools and services must meet the creative needs of the students, such as programming, editing music, video, images and text;

- Content: availability of the necessary content for the effective teaching and learning process and the integrity of the discipline.

M-learning technology suggests the electronic environment, which includes computing learning facilities and services, and the availability of web access to them from different mobile devices (Kuvshinov, 2007). M-learning allows to use wireless mobile applications for access to information and educational resources of the university, gives an opportunity to design educational electronic office for students and teachers. All these opportunities lead to academic mobility, personalized learning and differentiation of the learning process (Tremblay, 2010). 
Among the most important benefits of the implementation of m-learning in the higher education process we can name the following:

- Ubiquity: the possibility of obtaining information online;

- Availability: access to personal and learning resources through the wireless network;

- Convenience: the possibility to store personal data and necessary learning materials in mobile devices, instant connection to the Internet through a mobile phone;

- Personalization: the possibility of personalized learning.

In recent years, special attention is paid to the rapidly developing concept, named as BYOD ("Bring Your Own Device"), which is closely connected with the technology of mobile learning. The implementation of BYOD in teaching and learning process involves the introduction of technologies and services into the university educational environment which are focused on providing personalized access to information resources through mobile devices (curricula and programs, academic progress and attendance reports, results of the session, workload, timetable for a student and a teacher etc.); provision of distributed online access to content (podcast broadcasting, webinars, electronic magazines, personal library of educational and scientific resources, social media, etc.). Successful implementation of BYOD as a component of IT strategy of the higher education institution is due to the following factors (Ivanchenko, 2014):

- High level and dynamics of the spread of mobile devices in the student and teaching environment and sustained interest in their application, formed by outside socio-psychological factors;

- Significant cognitive potential of the students of a higher education institution, who are flexible enough and appropriately respond to changes in the established practices of the education process organization and easily adapt to new approaches and technologies;

- Learning materials can relatively easy be turned into media content and the content for interactive mobile services;

- Mobile services and content can be easily enough integrated into the infrastructure of educational and research space, both technologically and methodologically.

It is evident that education quality depends on the technologies which are applied to the teaching and learning process. Software for mobile devices interacts directly with the user, provides a link between students and educational system and greatly influences both the user's perception of the learning process in general and its final results. Developing and designing effective mobile applications is a complex process that involves multiple tasks. There are a number of modern tools and technologies to achieve a high level of developing and designing applications. In this connection, there are new requirements for the designing and developing educational mobile applications to make their implementation in the education process effective:

- Integration with various systems and e-learning services, for example, through the tools of joint activities and the feedback from a teacher (video conferencing, webinars, podcasts, etc.);

- Provision of the academic integrity and necessary amount of content for the effective learning and educational process;

- Delivery of learning materials in various forms and formats, depending on the preference of the student (text description, videos, audio lectures, and others);

- Provision of calculation functions, editing, visualization and modeling while connecting mobile devices to measuring instruments, various multimedia and office equipment;

- Ergonomics, simplicity and possibility to work with the educational web application easily and quickly;

- Stability, reliability and productivity, which provide effective and high-available operation of the application to a large number of students at the same time.

These factors lead to the increase in the number of tasks for mobile applications and their complexity. Consequently, one of the main aims of developing and designing mobile applications is to make them effective for supporting teaching and learning process.

In view of the above requirements, the Applied Mathematics and Informatics Department of Mari State University has developed and introduced m-learning system "Programming Mobile Applications for Android" into teaching and learning process of the university (Toktarova \& Blagova, 2014). It is an interactive learning system designed to deepen and consolidate the knowledge and skills of students in the field of programming 
mobile applications for Android.

Android is the operating system for smart-phones, tablet computers, e-books, digital players, watches, game consoles, net-books, smart-books and other devices (Android, 2015). The main advantages of developing and designing applications are free and open source software; possibility of replacing the built-in components with the upgraded versions, automatic control of the application lifecycle; high quality graphics and sound.

M-learning system "Programming Mobile Applications for Android" consists of six thematic modules: M1-Introduction to Android; M2-Development environment; M3-Application Development; M4-Application Components; M5-Interface Design; M6-Widgets. Each module is also divided into smaller structure units - blocks according to specific didactic purposes (Figure 1). For example, learning module M5 includes such elements as M5.1-Trees of representations, M5.2-Layout, M5.3-Initialization of representations, M5.4 — Standard layout, M5.5 - Interface Debugging.

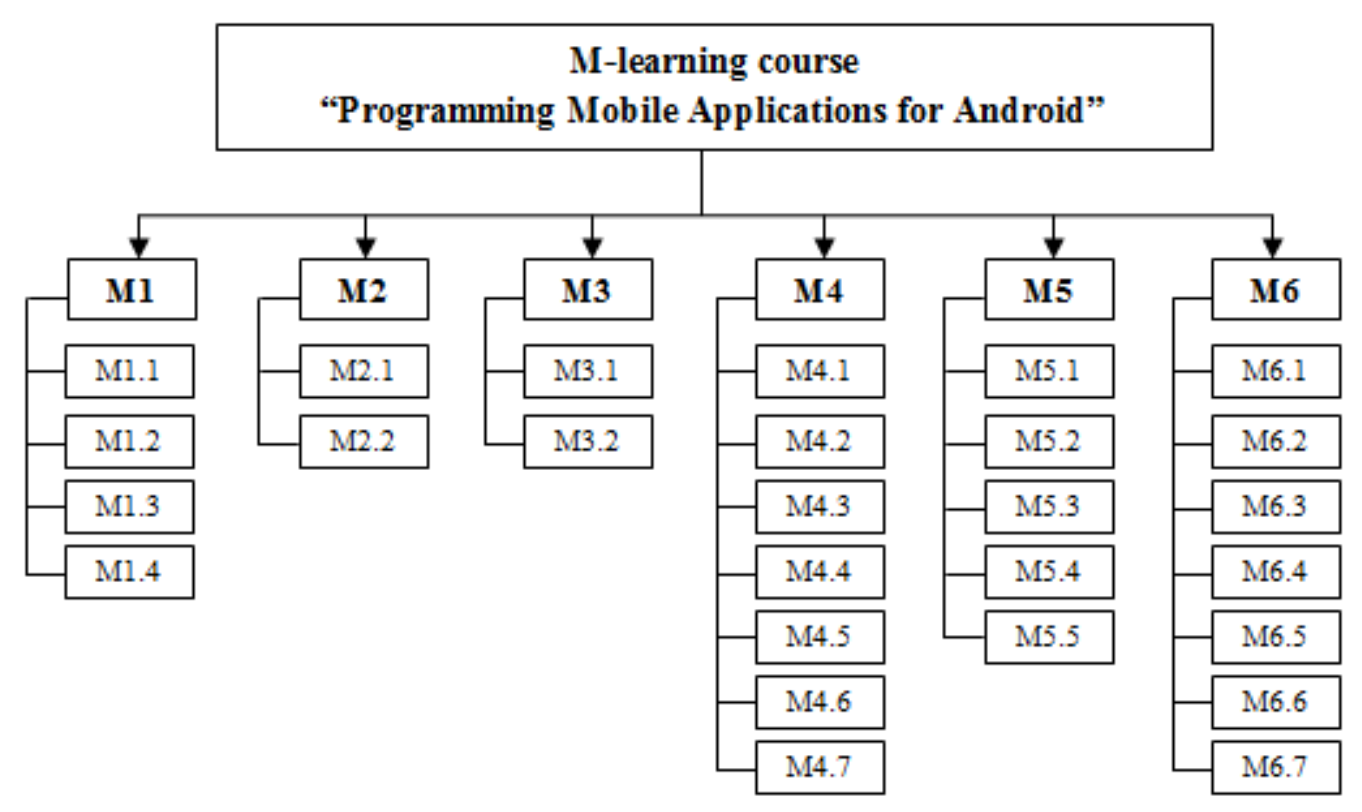

Figure 1. The modular structure of the course

The modular structure of the curriculum is based on the following principles:

- Selection of teaching and learning materials according to the educational aims and objectives and their inclusion to the target module;

- Complete, versatile and integrated teaching and learning materials in the module;

- Relative independence of the module, its logical completeness;

- Methodological support and possibility of feedback from the teacher.

The modular approach provides the flexibility and openness of the curriculum, that is, it provides students with opportunities to master learning materials of the whole training course in any sequence. In addition, while designing and analyzing the course structure we have defined such characteristics of the system as significance of the element in its structure. The number that characterizes current connections is called rank. While designing the structure of m-learning system, modules with high rank require careful didactic design. For example, elements 1.1- "Kernel level" and 1.2 - "Library level" have highest dominance value, that is why they were paid more attention; both the content of information frames and quality control of students' knowledge of course materials have been carefully thought out.

In accordance with the functional purpose, the following components of the learning system were defined. Theoretical subsystem is the main part of the system and is represented in the form of lectures that cover the most important and significant aspects of the studied material. The lecture course is built on a modular basis, allowing the user to determine not only the optimal sequence of studying the material, but also a comfortable 
pace of study. Additionally, audio and video lectures, presentations, lecture notes are designed for each chapter. Practical subsystem is represented in the form of laboratory work on the topics of the study units. It is designed to complement theoretical studies, demonstrate how knowledge taught in lecture courses can be put to use, provide and improve students' professional skills in the field of mobile application development. Laboratory work, in accordance with the theory of the gradual formation of knowledge and skills can be of three types of activity-oriented base (AOB): complete (all required orientations for performing an activity are included); incomplete (only main orientations for task solution and the example of the final result are given); invariant (general orientations are given). Control subsystem includes all the test materials: tests, examination tasks; it aims at quantitative and qualitative assessment of the level of mastering learning materials. After passing the course a student is given a detailed report, which includes the final assessment, the percentage of correctly performed tasks, indicator of the level of mastering the material, quality coefficient of mastering knowledge, time spent online during the studies, as well as a list of topics that should be revised. Additional information subsystem contains orientations for mastering the material, the user manual for the computer system installation and maintenance instructions.

The general model of teaching and learning process on the basis of m-learning system "Programming Mobile Applications for Android" is presented in Figure 2.

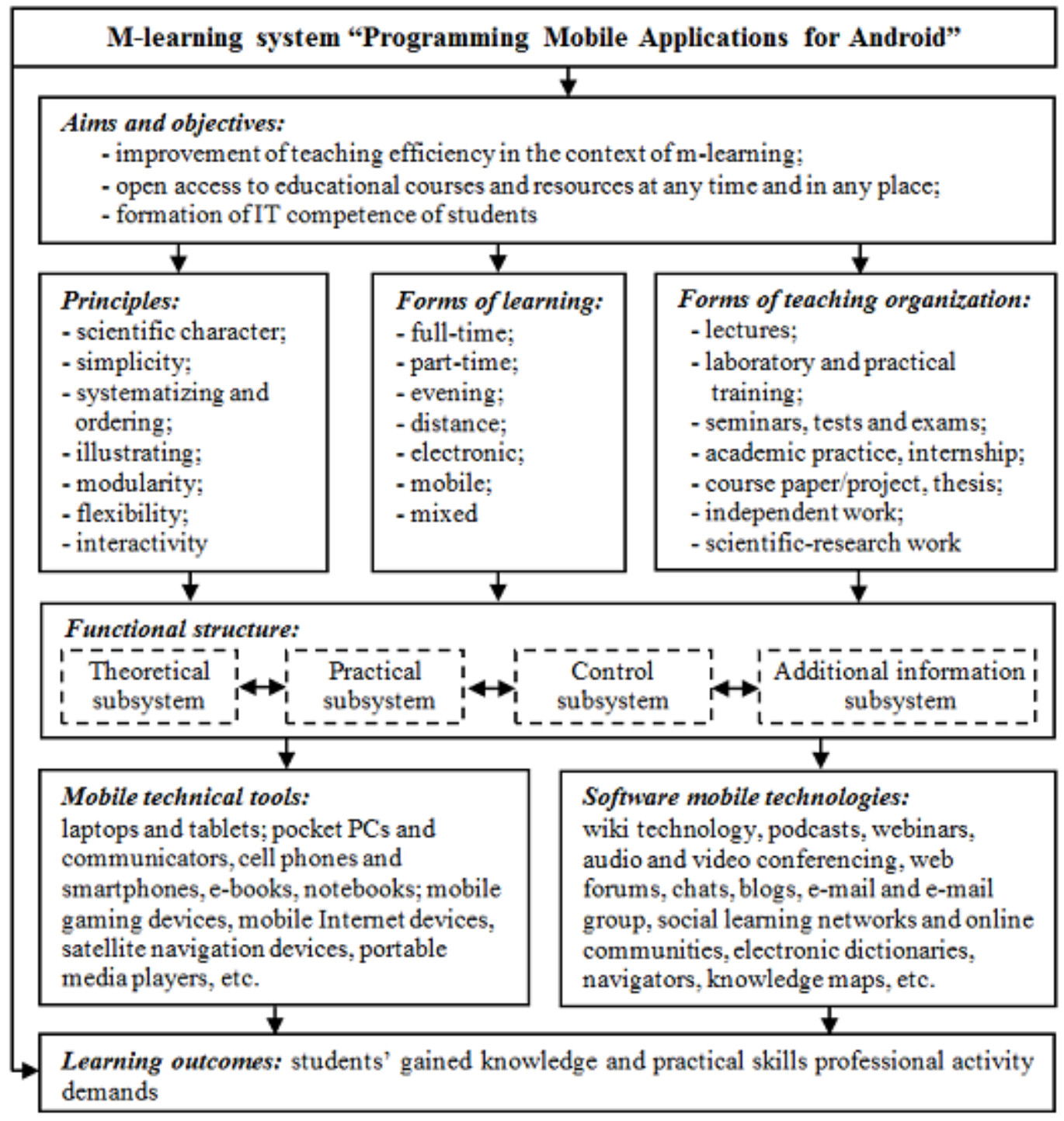

Figure 2. Implementation m-learning system model 
While developing the computer learning system, Java client-server technologies have been used, which have enabled to design versions for computers and a variety of mobile devices, provide access to Web services of communication (forum, chat, blogs), hold webinars, audio and video conferences, provide social interaction in educational networks and communities. The system provides three user access levels: administrator, teacher and student. The following review functions are accessible to the teacher: the performance rating of students, making a detailed report on the results of laboratory and tests performance, choice of the level of individual tasks for each student or group. In addition to working with learning materials and assignments, in a user account the student has an access to the results of laboratory work and tests with the possibility of unloading a detailed report as well as communicates with the teacher via the feedback form.

\section{Discussion}

In 2014 academic year designed m-learning system was tested in the framework of learning and teaching process with the third and fourth course students of 010400 "Applied Mathematics and Informatics" direction of training. To determine the technical readiness of learners and to analyze the use of mobile devices and applications, the survey was conducted. 86 students participated in the survey. The study highlighted that $100 \%$ of learners have phones (at least one), $86.0 \%$ of learners have smartphones and $83.7 \%$-laptops. Students were asked to answer the following questions:

- Would you like to study in the framework of m-learning system?

- Would you like to have possibility to download educational material in the mobile device?

- Do you think that mobile learning will improve education quality?

- Is it comfortable for you to use your mobile device to search for educational information online?

- Is there any need of designing educational mobile applications and their implementation in the learning and teaching process of the university?

The survey revealed that $97.6 \%$ of the students consider that the opportunity to download the educational material in the mobile devices will facilitate the learning process; $75.6 \%$ of the respondents would like to study in the framework of m-learning system. Moreover, $91.8 \%$ of students felt that the use of mobile learning will improve education quality, $98.8 \%$ of the learners believe that mobile devices are easy to use to search for learning resources online. $90.7 \%$ of the students consider that it is necessary to design mobile applications and implement them in the university educational process and $73.2 \%$ of the future programmers desired to become experts in designing mobile applications.

While analyzing basic mobile educational services used in the teaching and learning process, the following results were obtained. The most widely-used mobile applications are calculating means and calculators (96.5\%), online text translators $(93.0 \%) .86 .5 \%$ of the students pointed out the use of dictionaries and reference books on various branches of science, $73.2 \%$ of the respondents chose foreign language learning programs.

The main objective of the study was to assess the efficiency of the designed learning system in the context of mobile learning. The research was conducted in study hours during a semester. The level of mastering knowledge and skills was assessed on the results of control and independent works. The result revealed that this indicator in the pilot group is $11.5 \%$ higher than in other groups. The value of indicator of relevant efficiency of the volume of the mastered material is $15.8 \%$ higher than in a group where traditional methods were used. After completing the course, participants of the pilot group were asked to answer the questions; as a result, all the students noted that the designed m-learning system should be used extensively in delivering programming courses; $92.59 \%$ of the respondents consider that mobile learning increases students interest to the subject; $96.3 \%$ of the students believe that it increases the level of achievement through the access to learning materials, at any time and regardless of location.

\section{Conclusion}

The results of the experimental work suggest about the effectiveness of the designed m-learning system that contributes to the improvement of educational and methodical support of the university educational process. According to the study, m-learning system "Programming Mobile Applications for Android" was registered in the Official Bulletin of Rospatent "Computer Programs, Databases, Topographies of Integrated Circuits" (Certificate of the official registration of a computer program No. 2014618616, 26 August 2014) and has implemented in the learning and teaching process of the students of the Applied Mathematics and Informatics Department of Mari State University.

Promising ways of developing the m-learning system consist in efficiency and quality analysis of mobile 
learning in higher education institutions, design of mobile learning tools and resources, which will contribute to the implementation of lifelong learning strategies.

\section{Acknowledgement}

The present work is supported by the grant from the President of the Russian Federation for young scientists, No. MK-1634.2014.6

\section{References}

Al-Qahtani Awadh, A. Y., \& Higgins, S. (2013). Effects of traditional, blended and e-learning on students' achievement in higher education. Journal of Computer Assisted Learning, 29(3), 220-234. http://dx.doi.org/10.1111/j.1365-2729.2012.00490.x

Android. (2015). Android platform. Retrieved from http://www.android.com

Bondarouk, T., \& Ruël, H. (2011). Dynamics of e-learning: Theoretical and practical perspectives (Introduction to special issue). International Journal of Training and Development, 14(3), 149-154. http://dx.doi.org/10.1111/j.1468-2419.2010.00348.x

GOST R 53620-2009. (2011). Information and communication technologies in education(E-learning resources). Moscow: Standard-inform.

Ivanchenko, D. (2014). Informatization of university: Modern approaches and tools for implementation. Moscow: Oktopus.

Ivanchenko, D., Popov, S., \& Khmelkov, I. (2013). Mobile devices and services in higher education: The main barriers and directions of development. Remote and virtual learning, 12(78), 38-48.

Kuvshinov, S. (2007). M-learning is a new reality of education. Higher education in Russia, 8, 75-78.

OELPC. (2009). The Future OELPC: One Educational Laptop Per Child. Retrieved from http://www. olpcnews.com

Polat, E., Moiseeva, M., \& Petrov, A. (2006). Pedagogical technologies of distance learning. Moscow: The Academy.

On Education in the Russian Federation. (December 29, 2012). The Law of the Russian Federation (No. 273-FZ). Retrieved from http://www.consultant.ru

The Mobile Learning Network (MoLeNET). (2015). Mobile learning in practice. Retrieved from http://www. molenet.org.uk

Toktarova, V. (2013). Training and methodological support of the implementation of the main educational programs in the electronic educational environment of the higher education institution. Proceedings of the Volgograd State Pedagogic University, Series "Pedagogical Sciences”, 2(77), 28-32.

Toktarova, V., Blagova, A. (2014). Development and implementation of a computer learning system for programming mobile applications. Proceedings of the Southern Federal University. Pedagogical sciences, $11,63-71$.

Tremblay, E. (2010). Educating the Mobile Generation-Using personal cell phones as audience response systems in post-secondary science teaching. Journal of Computers in Mathematics and Science Teaching, 29(2), 217-227.

Wexler, S., Brown, J., Metcalf, D., Rogers, D., \& Wagner, E. (2008). ELearning guild research 360 report: Mobile learning. Santa Rosa, CA: eLearning Guild.

\section{Copyrights}

Copyright for this article is retained by the author(s), with first publication rights granted to the journal.

This is an open-access article distributed under the terms and conditions of the Creative Commons Attribution license (http://creativecommons.org/licenses/by/3.0/). 